the control of such serious diseases as smallpox, yellow fever, diphtheria and infestations with such animal parasites as the hookworms and the schistosomes. We should study the host-parasite relationship much more, including micro-organisms among the parasites, and get away from the rather narrow channels into which the very rapidity of the success of serological and immunological research has directed investigation. The whole picture should be studied by resuming broad biological and biochemical studies of the host and its bacterial and animal parasites. So far as the bacteria are concerned, the study of the complex property of parasites which we call virulence is important. A given parasite can cause epidemics or disease only when it has been able (1) to reach a susceptible host, (2) to overcome the cellular and humoral defences of that host, (3) to multiply in it, and (4) to damage it. Each of these factors can vary independently of the others. In order to cause an epidemic, the parasite must possess them all at the same time. A highly pathogenic strain of hæmolytic streptococci, for example, may have only a low degree of communicability, and the converse may be true of other strains. The study of the resistance of the host is likewise very important, and there are other factors which the epidemiologist must consider. Prof. Dubos believes that we shall eventually be able to predict the course of epidemics and to organize 'listening posts' which will detect qualitative and quantitative changes in the number of infectious agents and in those of their properties which affect their virulence. A beginning in this direction has already been made.

It is a matter for conjecture, Prof. Dubos considers, whether preventive chemotherapy will ever become advisable or effective, but preventive immunological treatment can certainly be effective, as immunization against smallpox, typhoid, diphtheria and other diseases has shown. High degrees of immunity produced by means of killed bacterial cultures are, however, very specific and do not protect against related organisms of another immunological type, so that typespecific immunity protects against only the particular organisms concerned. For this reason, effective immunization of whole populations with type-specific vaccines may be impossible. It is, nevertheless, possible in some instances, for example, the pneumococci, to direct the immune response against a component of the bacterial cell which is common to all types of pneumococci. Possibly bacterial cell components will be found in all bacterial groups which can be attacked in this way, so that we may eventually be able to immunize against all the types of each group. The non-specific immunization of this kind which has so far been achieved is, however, lower than that produced by type-specific vaccines; but more research into it might enable us to raise its potency. We have hitherto studied type-specific immunization almost exclusively. Immunization techniques, moreover, have been up to now primitive in their principle of killing the pathogenic organism with heat or antiseptics. It is certain that a very large percentage of the material injected in antityphoid vaccination has no immunological value at all and even causes unfavourable reactions in those to whom it is given. It is very important to isplate the chemical components of the cell which do produce the immunity. If we could do this, we might, in the distant future, prepare artificially the substances required to produce the immunity.

G. LAPAGE.

\section{ORGANIZATION OF INDUSTRIAL RESEARCH}

HUTURE historians will no doubt record that the opening decades of the twentieth century were charaeterized by the beginning of a systematic application of the results of scientific research to everyday life and the consequent foundation of research organizations, both large and small, mainly devoted to the best utilization of new knowledge in the service of commerce and industry. Moreover, these organizations, staffed by professional research workers together with technicians and other assistants in considerable numbers, stood out in striking contrast to the research conditions of the days of Faraday, Joule and Kelvin, when even advanced technological research was an entirely private venture. It is often forgotten to-day how young in years organized industrial research really is, and that while there are certain industries, such as heavy chemicals and electrical engineering, which have expanded on a vast scale with laboratories widely distributed over Great Britain, there are also other industries, deeply rooted in history, having as yet no medium for the exploration of fresh ideas and wholly dependent on traditional techniques.

At a meeting of the London Branch of the Institute of Physics on February 17, Dr. R. E. Slade, speaking from a wide practical experience, dealt with those factors which he regards as essential to the successful organization of research in the laboratories of manufacturing firms where most industrial research is now done.

Dr. Slade began by pointing out that the laboratory must be a well-run unit constituting an integral part of the firm's activities and in full sympathy with the industry which it is trying to serve. Research is admittedly an individualistic operation, and its success is not a mere question of organization, though organization can facilitate the performance of the work; for this reason, the director or research manager should himself be an experienced researcher, able to inspire the workers under him, but suiting his methods to the personalities of the various section leaders. "There is room in every laboratory for a scientifically trained organizer to do the administrative work for the director, so as to relieve him of as much administrative work as possible." The ideal chemical research laboratory would thus consist of a director and an administrator with six section leaders, five having charge of researches and the sixth looking after services including the library, analytical department and workshop. Probably the most efficient size of industrial chemical laboratory would. have sixty to a hundred university-trained workers and up to four hundred other workers. There is always a tendency for a laboratory to increase in size, but while it is cheaper to allow this rather than start a second new laboratory, it is not advisable to let the laboratory become so big that the director cannot know all his men and be prevented from exercising his personal influence and encouragement. "Not only do we want laboratories with distinctly different outlooks, but we want in.each laboratory men with different kinds of training who will look at problems in different ways and tackle them in different ways, too."

Dr. Slade does not believe that the direction of $a$ laboratory can be carried out effectively by a committee; he admitted the utility of advisory panels, but 
emphasized that the success of the laboratory depends upon the director being a research worker, capable of directing the laboratory, and having also the capacity of making a committee believe that it is directing the work when he is in reality leaving it to the common sense and ability of the section leaders. Moreover, if a company is to gain full value from its research department, there must be a director on the board of management who knows what research might do for it, and this director should himself have had research experience.

Industry must be alive to developments which may take place in any of the sciences ; for example, the chemical industry needs to employ mathematicians, physicists, metallurgists and biologists. In regard to physicists, it would seem that they have not in the past been used to full advantage, for they have often been engaged as narrowly specialized technicians such as X-ray crystallographers and spectroscopists, instead of being given the opportunity of examining industrial problems in their entirety and so determining how best physical knowledge may be applied and what factor needs to be measured and to what degree. Similarly, the metallurgist should not be brought in, for example, when pipes have already corroded and broken down, but should be given the opportunity to see that industry has pipes that will stand up to manufacturing conditions.

One of the great problems of present-day industrial research lies in the difficulty of acquiring new specialized techniques as they appear. No laboratory is big enough to keep a specialist in every possible technique, and so workers have to be sent to the originator of the technique as students. This method is too slow for industry, and Dr. Slade thinks that a national central laboratory of scientific techniques should be set up to serve industry in this field.

The cost of research is $£ 1,500-£ 3,000$ per annum per university-trained research worker employed, including assistants, mechanics, glass-blowers and services. Though high, the cost is fully justified by the results. Those carrying out research should have some authority to purchase equipment up to a reasonable sum, otherwise absurd cases will occur where men earning perhaps $£ 600$ a year or more are kept on unimportant work for weeks while a committee decides whether to spend $£ 60$ on a piece of apparatus.

Great importance should be attached to the linking of the research laboratory to the utilization of the products by the consumer; hence the director should learn to look at his problems from the point of view of the production manager and of the sales manager, and orient some of his researches accordingly.

After referring to the way in which the thirty research associations of Great Britain assist the special industries to which they are attached, Dr. Slade then described in detail a method of linking research and industry, as carried out at the Mellon Institute in America, where manufacturers may have a specific piece of work carried out by endowing a fellowship for a number of years ; in this way valuable work has been done on such diverse materials as limestone products, furs and their by-products, plastics, solvents, pesticides, rosins, high-boiling products, etc.

It is not in general desirable for university departments to carry out technological research; though industry has obtained its scientific outlook from the men it has recruited from the universities, and while important discoveries may be made in industrial laboratories, we shall always be dependent upon the universities for the most fundamental work and for new ideas, so nothing should be permitted to limit this vital function of the universities.

Dr. Slade concluded by stating that research thrives in an atmosphere of freedom, enthusiasm and achievement, and the aim of the organization of industrial research should be that of creating the best conditions for the individual workers with the view of applying knowledge and research to improve the arts of industry.

A particularly vigorous discussion followed the address, from which the following points, expressed perhaps in somewhat disjointed form, may be noted. Many good men are lost to research through promotion to administration. The researcher should have knowledge of what is practically possible in the craft of his industry; industry is suffering because problems are not being dealt with on a large enough scale, and there is need for co-operative research on a bold and comprehensive plan. Pooling of ideas will not result in lack of competition. A spirit of national service is requisite for industry in peace-time as well as in war-time. Workers should not be handicapped by having to write regular detailed reports of their work while it is in progress, but it is better to write a comprehensive report at the end. The cost of develop. ment and advertisement of results is bound to be relatively high in relation to the cost of the original research; it has therefore been suggested that exploratory research be limited by allocating, say, 20 per cent of research grants to original work and 80 per cent to development. The workshop is vital in research laboratories, and all workers should be able to carry out certain simple operations themselves and be able to make sketches of new apparatus, though very complicated drawings may be left to a draughtsman. Several speakers, including Dr. Slade, deplored any suggestion that a central committee should decide what fundamental work each laboratory should undertake; though the opposite view was also expressed that in the interests of humanity some direction should be given as to what are socially desirable researches.

H. LOWERY.

\section{FORTHCOMING EVENTS}

(Meeting marked with an asterisk * is open to the public)

\author{
Saturday, March 3
}

Geologists' Assoctation (at the Geological Society of London Burlington House, Piccadilly. London, W.1), at 2.30 p.m.-Annual General Hole, Torquay, and Mrs. Cazalet"' (Presidential Address).

Monday, March 5

ROYAI G̈EOGRAPHIOAL SOCIETY (at Kensington Gore, South Kensington, London, S.W.7), at 5 p.m.-Mr. J. M. Wordie : "NorthWest Greenland and North Baffin Island" (Kodachrome Film).

Socidity of ENGINAmRS (at the Geological Society, Burlington House, Piccadilly, London, W.1), at 5 p.m.-Mr. D. Tiranti : "The Need for Administrative Engineering".

association of a Ustrian Engingers, Chenists and SoIentific WORKERS IN GREAT BRITAIN (at the Austrian Centre, 69 Eton A venue, Hampstead, London, N.W.3), at 7.45 p.m.-Mr. E. A. Roth : "Technical and Economic Problems of Post-War Agrarian Policy in Central Europe".

Tuesday, March 6

ROYAI ANTHROPOLOGICAL INSTITUTE (at 21 Bedford Square, London W.C.1) at 1.30 p.m.-Dr. S. A. Hu7ayyin : "Further Light on the Upper Palrolithic of Egypt".

ROYAL INSTITUTION (at 21 Albemarle Street, London, W.1), at 5.15 p.m. -Sir Henry Dale, O.M. Pres.R.S.: "Nerve Endings and Chemical Transmitters", (1) "Actions of Involuntary Nerves and of Substances which Mimic or Paralyse their Effects". 